Farum

Sociológico

Forum Sociológico

Série II

25 | 2014

Número 25

\title{
Violência contra as mulheres: processos e contextos de vitimização
}

Joana Aguiar Patrício

\section{OpenEdition}

1 Journals

Edição electrónica

URL: https://journals.openedition.org/sociologico/902

DOI: 10.4000/sociologico.902

ISSN: 2182-7427

Editora

CICS.NOVA - Centro Interdisciplinar de Ciências Sociais da Universidade Nova de Lisboa

Edição impressa

Paginação: 33-43

ISSN: 0872-8380

\section{Refêrencia eletrónica}

Joana Aguiar Patrício, «Violência contra as mulheres: processos e contextos de vitimização», Forum Sociológico [Online], 25 | 2014, posto online no dia 10 novembro 2014, consultado o 29 março 2022 URL: http://journals.openedition.org/sociologico/902 ; DOI: https://doi.org/10.4000/sociologico.902

Este documento foi criado de forma automática no dia 29 março 2022.

(c) CICS.NOVA 


\title{
Violência contra as mulheres: processos e contextos de vitimização $^{1}$
}

\author{
Joana Aguiar Patrício
}

\section{NOTA DO AUTOR}

Pesquisa co-financiada pelo Programa Operacional Potencial Humano/Fundo Social Europeu (POPH/FSE) no âmbito de Bolsa de investigação da Fundação para a Ciência e a Tecnologia do Ministério da Ciência, Tecnologia e Ensino Superior (SFRH/

/BI/33013/2006).

1 Nas últimas quatro décadas, as práticas de violência nas relações privadas da família, sobretudo contra crianças e mulheres, foram progressivamente constituídas em problema social. Comummente denominada violência doméstica, a violência contra as mulheres na esfera familiar é uma questão prioritária nas agendas políticas internacionais e nacionais. Em 2011, o Parlamento Europeu define a Política-quadro para o Combate à Violência contra as Mulheres e o Conselho da Europa estabelece a Convenção para a Prevenção e o Combate à Violência contra as Mulheres e a Violência Doméstica, documento ratificado por Portugal em 2013 e em vigor a partir de 1 de Agosto 2014. Internamente, vários países europeus concretizam planos nacionais de combate à violência e discriminação das mulheres. Em Portugal, em 2000, a violência doméstica assume a natureza de crime público (Lei n.. 7/2000). Mais recentemente, autonomiza-se no Código Penal, estipulando-se o crime de violência doméstica (Lei n. ${ }^{\circ}$ 59/2007), as suas vítimas são objeto de proteção específica (Lei n. 112/2009). Desde o final dos anos noventa executaram-se consecutivamente quatro planos nacionais contra a violência doméstica (PNVD). O V Plano Nacional de Prevenção e Combate à Violência Doméstica e de Género (2014-2017) está em execução. 
2 A investigação e os sucessivos debates teórico-metodológicos têm contribuído para a redefinição do objeto e formulação de políticas de combate à violência. A problematização encetada pelos movimentos feministas da década de setenta, focada na violência conjugal contra as mulheres, progrediu, identificando-se novas dimensões da violência no casal - e. g., a vitimização dos homens, a violência em casais do mesmo sexo, a violência sexual entre parceiros/as íntimos/as, a violência no namoro.

$\mathrm{O}$ artigo procura analisar a vitimização das mulheres enquanto processo cumulativo, um processo paralelo ao decurso da vida da mulher, uma questão suscitada por pesquisa anteriormente realizada (Patrício, 2010). A perspetiva da vitimização enquanto processo cumulativo e não circunscrito a determinada etapa da vida ou contexto social é recente (e.g., Anderson, 2010). A informação do Inquérito Nacional Violência de Género $^{2}$, realizado em 2007, permite uma análise exploratória e comparativa dos processos e contextos da vitimização sexual, física e psicológica, declarados por mulheres vítimas de violência sexual.

4 As particularidades da vitimização sexual dificultam o conhecimento sobre o problema. Primeiro, o não reconhecimento da violência sexual no casal compromete a sua aferição e pode originar um predomínio das violências física e psicológica em estudos sobre violência no casal. Segundo, o assédio sexual é referenciado por mulheres mais jovens, por vezes sem experiência conjugal ou de coabitação, e em contextos de ocorrência externos à família (Patrício, 2010). A diversidade da vitimização sexual ao nível de vítimas e dos contextos condiciona uma pesquisa conjunta, escasseando, ao mesmo tempo, a pesquisa de formas distintas de violência sexual.

5 Na linha de pesquisas mais recentes, propõe-se uma análise da vitimização enquanto processo iniciado na infância ou juventude e desenvolvido no curso de vida da mulher. Constituído por episódios únicos ou replicados ao longo da vida, a noção de processo de vitimização permite equacionar a coexistência de relações violentas, não circunscritas ao contexto do casal ou da família, ou a um único tipo de violência. Neste artigo dá-se conta dos resultados a que se chegou, examinando a vitimização sexual, física e psicológica declarada pelas vítimas de violência sexual.

\section{Estado da arte}

6 Até muito recentemente, a vitimização foi analisada de forma compartimentada, isolando-se fases da vida, tipos de violência e contextos de perpetração. A crescente relevância do fenómeno da violência como um processo relacional e integrado no curso de vida do indivíduo permite ultrapassar a cisão entre vitimização na infância e adolescência e a vitimização em idade adulta (e. g., Anderson, 2010; Krebs, Breiding et al., 2011; Carbone-Lopez, Renninson et al., 2012). Em 2001, Macmillan referia a conexão entre o risco de vitimização e a idade da vítima. Segundo o autor, parte substancial da vitimização violenta antecede a transição para a idade adulta comprometendo o desenvolvimento do indivíduo. Importa avaliar o impacto da vitimização no curso de vida (idem), nomeadamente, ao nível das suas consequências para o indivíduo, e relacionar a vitimização familiar ao longo da vida (Williams, 2003) e com contextos de vitimização externos à família.

7 A vitimização enquanto processo múltiplo e cumulativo é objeto de pesquisas, sobretudo centradas na infância e adolescência. Finkelhor e equipa introduzem o 
conceito de polivitimização e consideram polivítimas as crianças e jovens que experienciaram quatro ou mais tipos de vitimização durante um ano (e.g., Finkelhor, Ormrod et al., 2007a e 2007b). Entre crianças e jovens, a polivitimização é um forte preditor de sintomas de trauma e de problemas psicológicos (Finkelhor, Ormrod et al., 2007a; Ellonen e Salmi, 2011). Para além disto, as polivítimas têm maior probabilidade de serem vitimadas por pares na escola, familiares em casa, ou por pessoas da vizinhança ou da comunidade envolvente (Turner, Finkelhor et al., 2010); e correm um risco elevado de serem polivitimizadas no ano seguinte (Finkelhor, Ormrod et al., 2007b).

Devido à severidade inerente aos atos sexuais e às consequências que implica para a vítima, a pesquisa sobre a coocorrência da violência torna-se relevante entre as vítimas de violência sexual. A partir do National Survey of Children's Exposure to Violence, Turner, Finkelhor e Ormrod (2010) concluem que a violência sexual é provavelmente mais experienciada por crianças polivítimas do que por outras crianças vitimadas. Por outro lado, as crianças vítimas de abuso sexual apresentam maior propensão para serem polivítimas (Finkelhor, Ormrod et al., 2007a). A equipa de Finkelhor conclui que para algumas crianças a vitimização não se restringe a um episódio único, e é antes uma condição de vida à qual acrescem os efeitos da adversidade experienciada, efeitos que se acumulam e perduram no tempo (Turner, Finkelhor et al., 2010), um aspeto que deve ser ponderado na pesquisa sobre a vitimização adulta.

Em geral, escasseiam as investigações sobre a coocorrência de tipos e contextos de vitimização em indivíduos adultos, sobretudo quando envolve violência sexual. A partir do estudo norte-americano National Intimate Partner and Sexual Violence Survey 2010, Black e equipa (Black, Basile et al., 2011) expõem a severidade implícita na vitimização sexual e a coocorrência de outras formas de violência. Nos EUA, durante a sua vida, perto de uma em cada cinco mulheres foi violada (idem). Entre as mulheres vítimas de violação destaca-se a perpetração por indivíduos próximos da vítima, nomeadamente, parceiros íntimos e conhecidos (respectivamente $51,1 \%$ e 40,8 \% das vítimas); e, com menor relevância, a violação por indivíduos estranhos (15,1 \% das vítimas) (idem). Para a maior parte das vítimas de violação completa, a primeira violação é bastante precoce: para $42,5 \%$ das vítimas o primeiro episódio deu-se antes de completarem 18 anos, percentagem que ascende aos $80 \%$ ao considerar-se um primeiro episódio antes dos 25 anos de idade (idem). $O$ inquérito norte-americano expõe a severidade da violência contra as mulheres mais jovens: além de as mulheres serem fortemente vitimadas por violência sexual, perseguição e violência do parceiro íntimo, muitas das vezes, o primeiro episódio ocorre durante a infância, repetindo-se entre as jovens que têm entre 18 e 24 anos (idem: 83). Paralelamente, entre as vítimas de violência do parceiro íntimo, estima-se que mais de uma em cada três mulheres tenha sido vítima de múltiplas formas de violação, perseguição ou de violência física; e que ao longo da sua vida cerca de uma em cada dez mulheres tenha sido violada por um parceiro íntimo (idem). Este estudo revela também que, ao longo da sua vida, cerca de uma em cada duas mulheres foi vítima de violência sexual que não uma situação de violação (idem).

Para Krebs, Breiding et al. (2011), importa conhecer os processos da múltipla vitimização de adultos e aferir as consequências da sobreposição dos tipos de violência no curso de vida das vítimas, sobretudo ao nível da violência sexual pelo parceiro íntimo. Já na década de oitenta, Frieze focava a associação entre violência física e coerção sexual e a violação entre mulheres casadas (1983, ref. idem). Mais 
recentemente, Marshall e Holtzworth-Munroe mostram que a perpetração de violência física e agressão psicológica por parte do marido está significativamente relacionada com a perpetração de violência sexual; e que a violência física e agressão psicológica por parte dos maridos predizem a coerção sexual (2002, ref. idem). Somente o exercício de violência física pelos maridos prediz a perpetração de sexo forçado por esses maridos, na forma tentada ou efetiva (idem, ref. idem). Em consonância com outros estudos, os maridos fisicamente mais violentos perpetram a violência com um carácter mais sexual (1994, Holtzworth-Munroe e Stuart, ref. idem).

11 A partir do National Intimate Partner and Sexual Violence Survey Pilot Study, estudo representativo da população dos EUA de mulheres adultas com 18 ou mais anos, e com recurso a métodos estatísticos multivariados, Krebs, Breiding et al. (2011: 489) avaliam a sobreposição das experiências de violência física, violência sexual, agressão psicológica e perseguição por parceiros íntimos e não íntimos. Considera-se vitimização por violência sexual os casos reportados de tentativa ou ato de relações sexuais não desejadas pelo parceiro íntimo com penetração oral, vaginal e/ou anal; incluindo o contato através da força, intimidação ou incapacitação da vítima (idem). Os investigadores constatam que, entre as mulheres com experiência de vitimização sexual perpetrada pelo parceiro íntimo, a maior parte foi também vítima de violência física pelo parceiro $(70,3 \%)$ e de violência psicológica $(89,3 \%)$ pelo parceiro (idem). Os atos de perseguição, violência sexual e abuso emocional por um parceiro íntimo encontram-se positivamente relacionados com a probabilidade de a vítima experienciar violência física por um parceiro íntimo (idem). Os fatores associados a uma maior probabilidade em ser vítima de violência sexual por um parceiro íntimo são o ter sido vítima de perseguição, de violência física, ou de agressão psicológica por um parceiro íntimo (idem: 494).

Por sua vez, Carbone-Lopez, Rennison et al. (2012) adotam a perspetiva da vitimização enquanto processo desenvolvido ao longo da vida e focam padrões de vitimização nas relações de intimidade presentes e passadas. Com base no National Violence Against Women Survey, EUA, os autores concluem que as mulheres com experiência de violência grave no contexto do relacionamento íntimo têm maior probabilidade de ter um novo relacionamento igualmente violento (idem). Paralelamente, a precocidade na experiência de violência perpetrada pelos pais tem profundas implicações para o desenvolvimento e manutenção das relações de intimidade em idade adulta, bem como as experiências de violência nesses relacionamentos (idem). Carbone-Lopez, Rennison et al. (2012) avançam com aspetos importantes para explicar a continuidade ou a interrupção do processo de vitimização: a agência e a capacidade do indivíduo para mudar, e a aquisição de recursos e de elementos-chave para sair do padrão de relação violenta.

Para conhecer o/os processo/s de vitimização do indivíduo importa comparar os contextos de vitimização, a singularidade ou a repetição de determinada situação de violência. Quer o episódio esporádico, quer a situação de violência continuada e padronizada, cometidos por desconhecidos/as ou conhecidos/as da vítima, têm um impacto no curso de vida do indivíduo (Macmillan, 2001). Porém, a investigação sobre o fenómeno raro e ocasional parece escapar à pesquisa centrada no fenómeno rotineiro e duradouro (e. g., Elder, 1974, cit. Macmillan, 2001), aspetos que devem ser considerados na investigação sobre os contextos de ocorrência e formas de violência sexual. Para 
White (2009), os estudos longitudinais assentes em grandes amostras permitem conhecer o impacto da violência familiar no curso de vida do indivíduo.

Perante as investigações quantitativas internacionais referidas e no quadro do Inquérito Nacional Violência de Género (Lisboa, Barroso et al., 2009) é possível analisar a vitimização das mulheres enquanto processo cumulativo. As vítimas de violência sexual têm maior propensão para serem vítimas de violência mais severa, e embora o conceito de polivitimização de Finkelhor e equipa (2007a) não seja aqui aplicado, procura-se conhecer a severidade e o impacto da violência na vida das vítimas de violência sexual. A pesquisa longitudinal permite compreender o modo como os contextos de vitimização se sucedem no curso da vida da mulher: infância, juventude, idade adulta, velhice. Paralelamente permite discernir a relação entre práticas de violência no namoro e no contexto da conjugalidade ou da coabitação, uma questão importante, já que, por um lado, em inquéritos nacionais de vitimização de mulheres adultas sobressai a violência conjugal (e. g., Lisboa, Barroso et al., 2009), e, por outro lado, pesquisas nacionais com jovens mostram a violência no namoro como forte preditor de violência conjugal (e.g., Machado, Caridade et al., 2010), um elemento que contribui para o agravamento no processo de vitimização em idade adulta. Dado que, em estudos nacionais, entre a vitimização sexual sobressai a relacionada com situações de assédio e que é declarada por mulheres mais jovens (Patrício, 2010), procura-se discernir as diferentes formas de vitimização sexual no curso de vida da mulher. Neste contexto, colocam-se quatro questões. Primeira, o que distingue a vitimização e a perpetração de violência sexual das restantes formas de violência? Segunda, qual é o grau de severidade da violência experienciada por vítimas de violência sexual? Terceira, como se iniciam e desenrolam diferentes processos de vitimização ao longo da vida da vítima? Quarta e última questão, quais as dinâmicas associadas a contextos de vitimização distintos?

15 A partir de um conjunto de variáveis do questionário Inquérito Nacional Violência de Género e tendo em conta que a informação recolhida reflete a perceção das inquiridas sobre a sua vitimização e a forma como a declaram a terceiros, pretende-se conhecer o modo como as relações e as dinâmicas de vitimização por violência sexual, física e psicológica se estabelecem em contextos distintos. A análise tem como fio condutor a idade da vítima quando determinado ato de violência ocorre pela primeira vez. Parte-se do pressuposto de que a idade da mulher no primeiro episódio de determinado ato de violência condiciona o ato de violência, o tipo de relação com o/a perpetrador/a e, consequentemente, os espaços de ocorrência, as reações e os motivos associados a essa vitimização.

16 A pesquisa tem um caráter exploratório e visa aprofundar a perspetiva da vitimização enquanto processo cumulativo no quadro da informação recolhida no estudo quantitativo nacional, sem pretensões de assumir a complexidade analítica de estudos internacionais anteriormente referenciados, uma vez que os dados o não permitem.

\section{Metodologia}

O artigo centra-se na análise da vitimização declarada por mulheres que sofreram alguma forma de violência sexual e decorre de pesquisa anterior sobre violência sexual no feminino ${ }^{3}$ (Patrício, 2010). Consideram-se 53 atos de violência repartidos da seguinte forma: 26 atos de violência psicológica, 14 de violência física e 13 atos de violência 
sexual (idem). Os atos de violência sexual foram categorizados em três géneros: assédio sexual; relação sexual forçada; e pornografia, aborto ou gravidez forçada, o que permite comparar a diversidade de contextos da vitimização sexual (ver Gráfico 1) (Patrício, $2010)^{4}$.

A pesquisa reporta-se às vítimas de violência sexual (112 mulheres) e aos atos de violência física, sexual e psicológica por elas referenciados (396 casos) no Inquérito Nacional Violência de Género (idem). Procedeu-se a uma análise de dados univariada e bivariada com recurso aos programas SPSS e EXCEL. Face aos objetivos propostos, calculou-se a idade da mulher aquando da sua primeira vitimização por cada ato de violência sexual, psicológica ou física (informação obtida para 348 casos de violência, cerca de $88 \%$ dos casos). Para os 396 casos de violência registados, analisam-se as respostas com informação válida para as variáveis: idade da mulher; situação conjugal; idade da mulher quando vitimada pela primeira vez; tipo de violência; relação de parentesco com o/a perpetrador/a; local de ocorrência do ato; reação ao ato de violência; motivo atribuído ao ato de violência. $\mathrm{Na}$ análise dos atos de violência, o caso reporta-se ao ato e não ao indivíduo-vítima (Patrício, 2010).

\section{Resultados}

Ao longo da vida, as mulheres são confrontadas com diversos contextos de vitimização. Os processos de vitimização das vítimas de violência sexual, declarados no Inquérito Nacional Violência de Género, iniciaram-se na juventude das vítimas e antecedem uma primeira situação de conjugalidade: $40 \%$ das vítimas sexuais tem entre os 18 e 34 anos e $35 \%$ é solteira (Patrício, 2010). As vítimas de violência sexual são relativamente mais jovens do que as vítimas de atos de violência psicológica e/ou física, inquiridas no estudo nacional (idem).

As vítimas de violência sexual não foram apenas vítimas de atos sexuais. A violência sexual representa $36 \%$ da violência por elas declarada ${ }^{5}$, sobretudo situações de assédio sexual como "frases com duplo sentido e obscenidades" (Gráfico 1). Se para a maior parte das mulheres, a vitimização sexual se reporta a situações de menor gravidade, como o assédio sexual (74\% das vítimas), o inquérito nacional expõe uma realidade mais severa, por vezes ocultada ou menos reconhecida pelas mulheres: as relações sexuais forçadas na forma tentada ou consumada (idem). Para $14 \%$ das vítimas, a violência sexual circunscreve-se a relações sexuais forçadas, atos que representam perto de $14 \%$ da violência sexual relatada (idem) (Gráfico 1). 
Gráfico 1 [5.⿴囗十 Episódios de violência sexual $(n=163)(\%)$

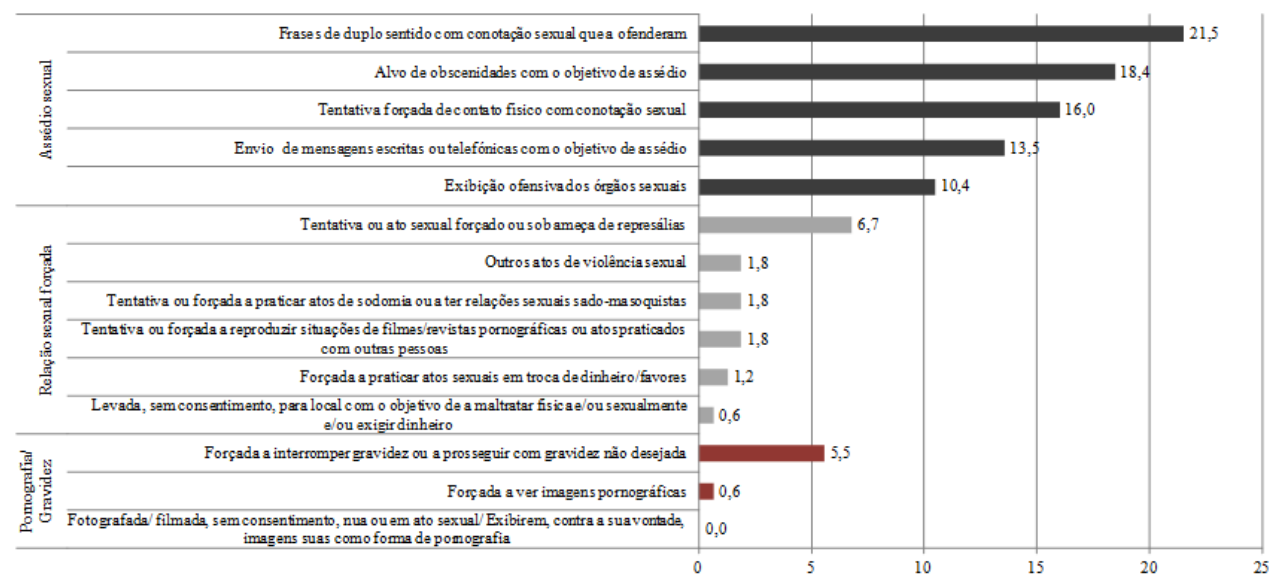

Fonte: Patrício, 2010.

Fonte dos dados: Inquérito Nacional Violência de Género, CIG, CesNova/FCSH-UNL.

21 A severidade da violência experienciada pelas mulheres pode ser aferida de várias formas. Em primeiro lugar, a precocidade no início do processo de vitimização. Para cerca de 30 \% das vítimas, o primeiro episódio de violência sexual, física ou psicológica registou-se antes de completarem 18 anos, percentagem que ultrapassa a metade das vítimas, se se considerar uma primeira vitimização antes dos 25 anos de idade (Gráfico 2). Em segundo lugar, as vítimas de violência sexual são objeto de atos de natureza física, sexual e/ou psicológica: à data do estudo, 23,2 \% das inquiridas tinha sido vítima de cinco ou mais atos de violência. Somente 30,4\% das mulheres mencionou um único ato de violência. Em terceiro lugar, a vitimização declarada pelas vítimas de violência sexual indicia uma severidade que coloca em risco a vida da mulher: $17 \%$ das vítimas refere casos de violência que de forma explícita ou implícita colocam a sua vida em risco como as "ameaças com arma de fogo ou branca", "ameaças e chantagens do tipo "mato-te»", "apertarem-lhe o pescoço", "empurrões pela escada abaixo/contra objetos", "sovas", "bater com a cabeça contra a parede/chão" e "atirarem-lhe objetos"; entre estas vítimas, mais de metade referiu mais do que um ato deste tipo, o que representa um cenário de vitimização severo. Importa pois conhecer o início do processo de vitimização e discernir o modo como diferentes tipos e contextos de vitimização se intercalam e sucedem no curso de vida das mulheres. 
Gráfico 2 圈 Idade das mulheres quando ocorreu o primeiro episódio de violência sexual, psicológica ou física $(n=112)(\%)$

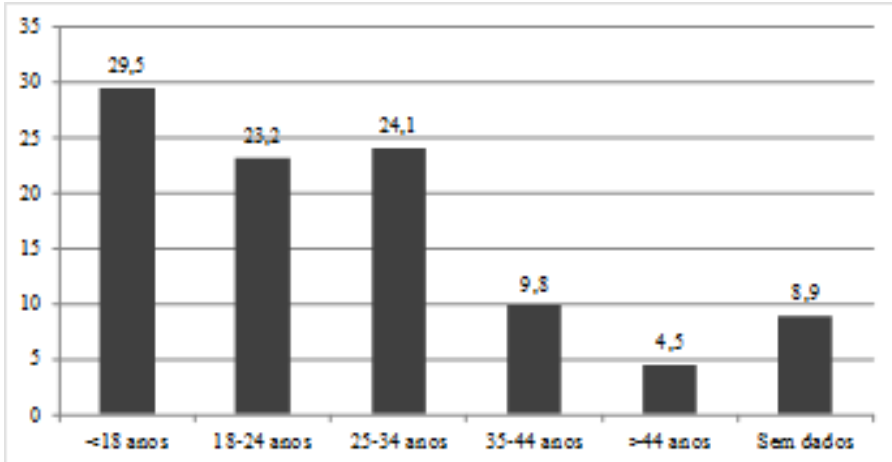

Fonte dos dados: Inquérito Nacional Violência de Género, CIG, CesNova/FCSH-UNL.

A informação do Inquérito Nacional Violência de Género revela que desde a juventude as vítimas sexuais são, sucessivamente, confrontadas com novas situações de violência, sobretudo de violência psicológica e assédio sexual (Gráfico 3). Excetuando as situações de pornografia, gravidez e aborto forçados, os restantes tipos de violência ocorrem pela primeira vez antes de as mulheres completarem 18 anos. Note-se o caso das relações sexuais forçadas que começam antes da maioridade das vítimas e expõe a gravidade da violência contra crianças e jovens (Gráfico 3).

Gráfico 3 圈 Idade da mulher quando ocorreu o primeiro episódio de cada ato de violência por tipo de violência $(n=348)(\%)$

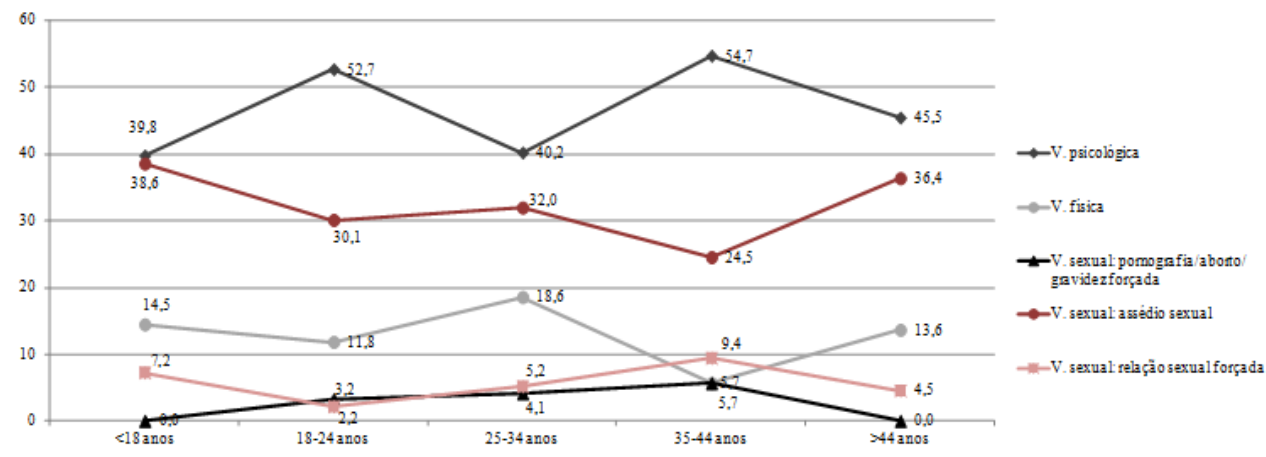

Fonte dos dados: Inquérito Nacional Violência de Género, CIG, CesNova/FCSH-UNL.

A violência contra a mulher tem lugar em variados contextos. $O$ estudo nacional afere a vitimização no contexto do casal, da família, da escola, do trabalho, entre outros. Coloca-se a hipótese de, no processo, de vitimização, o tipo de relação entre a vítima e o/a aperpetrador/a não variar substancialmente, excetuando, talvez, no domínio das relações de intimidade (e.g., namorado/a,cônjuge/parceiro, ex-cônjuge/ex-parceiro/ ex-namorado). Para 345 casos de violência determinou-se o tipo de relação entrevítima e perpetrador/a de acordo com a idade da mulher quando o ato ocorreu pela primeira vez (Gráfico 4). 
Gráfico 4 臨 Idade da mulher quando ocorreu o primeiro episódio do ato de violência por tipo de relação com o/a perpetrador/a $(n=345)(\%)$

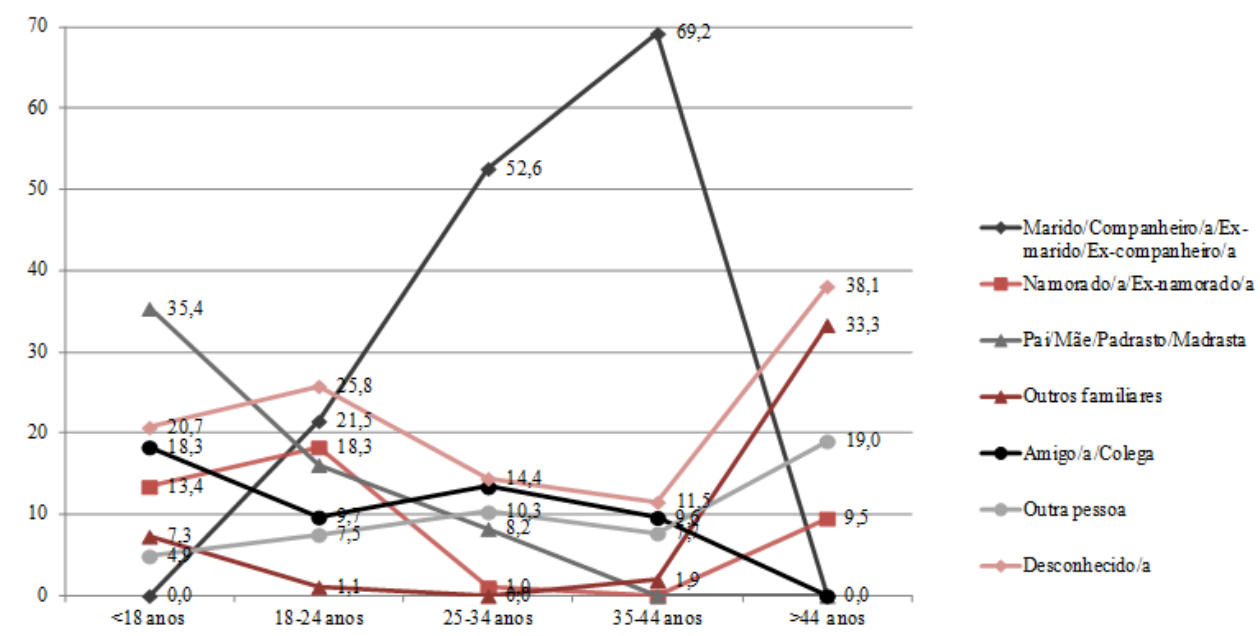

Fonte dos dados: Inquérito Nacional Violência de Género, CIG, CesNova/FCSH-UNL. namorado/a, atuais ou passados -, a violência declarada revela um dado interessante (Gráfico 4). Por um lado, entre os atos referenciados sobressaem os que se iniciaram quando a mulher tinha entre 18 e 44 anos de idade. Durante vinte e cinco anos, maridos/companheiros e/ou ex-maridos/ex-parceiros são os principais perpetradores de novos atos de violência contra estas mulheres. Entre os atos que ocorreram pela primeira vez quando a mulher tinha entre 25 e 44 anos, mais de metade foi perpetrada pelos maridos/companheiros e/ou ex-maridos/ex-parceiros das vítimas. o estudo nacional aponta para uma sequência no processo de vitimização, que acompanha as alterações no curso de vida da mulher, nomeadamente a transição da fase do namoro para a conjugalidade e/ou coabitação. Assim, e embora a violência no namoro não surja de forma tão destacada devido ao reduzido número de casos, a informação disponível sugere que entre os atos iniciados entre os 25 e os 44 anos da mulher, a perpetração por namorados/as é"convertida" na perpetração pelo marido/companheiro e/ou exmarido/ex-companheiro das vítimas. Após os 44 anos de idade, verifica-se uma redução no número de novos atos de violência no casal; ao invés, as mulheres referem novos atos perpetrados por outros familiares (Gráfico 4). Por seu turno, os/as desconhecidos/ as figuram entre os principais perpetradores de novos atos de violência ao longo da vida das mulheres inquiridas.

Quanto ao ato de violência em si, os perpetradores exercem tipos de violência diferenciados (Quadro 1). Os maridos, companheiros e namorados, atuais ou passados, bem como os pais, mães, padrastos e madrastas das vítimas exercem sobretudo violência psicológica. Já os desconhecidos/as, os amigos/as e colegas da vítima surgem como os autores de assédio sexual. Entre a violência cometida por outros familiares sobressai a violência física, tipo de violênciaque se destaca também entre a violência exercida no contexto conjugal e parental. Os namorados e ex-namorados, para além do 
exercício da violência psicológica, surgem como os autores do assédio sexual. Ao nível das relações sexuais forçadas, a informação expõe o contexto familiar da sua perpetraç ão, destacando-se os maridos e companheiros (atuais ou passados), e os pais e padrastos das vítimas como os perpetradores. Dos vinte e três casos relatados, somente um caso de relação sexual forçada foi cometido por um desconhecido, o que permite perceber a perpetração de formas gravosas de violência sexual no círculo muito próximo da vítima.

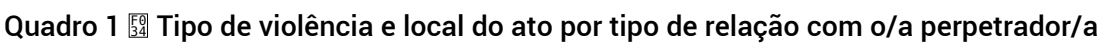

\begin{tabular}{|c|c|c|c|c|c|c|c|c|c|}
\hline & & \multicolumn{8}{|c|}{ Tipo de relação com perpetrador/a } \\
\hline & & 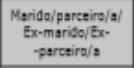 & 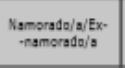 & 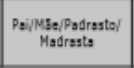 & $\begin{array}{l}\text { Outros } \\
\text { tamliares }\end{array}$ & Amigo/a/Colegs & Outrs pessos & Descentlecido/s & Total \\
\hline \multicolumn{10}{|l|}{ Tipo de violência } \\
\hline V. psicológica & $\begin{array}{r}n \\
\%\end{array}$ & $\begin{array}{ll}66 & \\
58,9\end{array}$ & $\begin{array}{ll}21 & \\
& 65,6\end{array}$ & $\begin{array}{ll}45 & \\
& 67,2\end{array}$ & ${ }^{4} 25,0$ & ${ }^{7}{ }_{15,6}$ & ${ }_{46,9}^{15}$ & ${ }^{17} 20,0$ & $\begin{array}{l}175 \\
45,0\end{array}$ \\
\hline \multirow{2}{*}{ V. física } & $n$ & 24 & 2 & 17 & 6 & 3 & 0 & 3 & 55 \\
\hline & $\%$ & 21,4 & 6,3 & 25,4 & 37,5 & 6,7 & 0,0 & 3,5 & 14,1 \\
\hline \multirow{2}{*}{$\begin{array}{l}\text { V. sexual: gravidez forçada; } \\
\text { aborto; pornografia }\end{array}$} & $n$ & 7 & 1 & 1 & 0 & 0 & 0 & 0 & 9 \\
\hline & $\%$ & 6,3 & 3,1 & 1,5 & 0,0 & 0,0 & 0,0 & 0,0 & 2,3 \\
\hline \multirow{2}{*}{ V. sexual: assédio sexual } & $n$ & 4 & 8 & 0 & 4 & 32 & 15 & 64 & 127 \\
\hline & $\%$ & 3,6 & 25,0 & 0,0 & 25,0 & 71,1 & 46,9 & 75,3 & 32,6 \\
\hline V. sexual: relação sexual forçada & $n$ & $\begin{array}{ll}11 & \\
& 9.8\end{array}$ & 0 & 4 & 2 & $\begin{array}{ll}3 & \\
& 67\end{array}$ & $\begin{array}{lll}2 & & \\
& 6 & \end{array}$ & 1 & 23. \\
\hline Total & $n$ & 112 & 32 & $\begin{array}{rr}67 \\
\quad 100 \\
\end{array}$ & $\begin{array}{r}16 \\
100\end{array}$ & $45 \begin{array}{ll}45,7 \\
100\end{array}$ & $\begin{array}{r}32 \\
100\end{array}$ & $85_{100}^{1,2}$ & $\begin{array}{c}389 \\
100\end{array}$ \\
\hline \multicolumn{2}{|l|}{ Local do ato } & & & & & & & & \\
\hline Casa & $\begin{array}{l}n \\
\%\end{array}$ & ${ }^{105} 87,5$ & ${ }^{15} 31,9$ & $\begin{array}{ll}49 & \\
81,7 & \end{array}$ & ${ }_{73,3}^{11}$ & ${ }^{8} 16,3$ & ${ }^{9} 25,7$ & $\begin{array}{ll}5 & \\
& 5,8\end{array}$ & $\begin{array}{l}202 \\
49,0\end{array}$ \\
\hline Trabalho & $\begin{array}{l}n \\
\%\end{array}$ & $\begin{array}{ll}1 & \\
& 0,8\end{array}$ & $\begin{array}{ll}0 & \\
& 0,0\end{array}$ & $\begin{array}{ll}0 & \\
& 0,0\end{array}$ & 0,0 & 9 & ${ }^{14} 40,0$ & 4,7 & ${ }^{28} 6,8$ \\
\hline Escola & ${ }^{n}$ & $\begin{array}{ll}0 & \\
& 0,0\end{array}$ & ${ }^{6}{ }_{12,8}$ & $\begin{array}{ll}0 & \\
& 0,0\end{array}$ & 0,0 & ${ }^{15} 30,6$ & \begin{tabular}{ll|}
1 & \\
& 2,9
\end{tabular} & $\begin{array}{ll}0 & \\
& 0,0\end{array}$ & ${ }^{22} 5,3$ \\
\hline Espaços públicos/Rua & $\begin{array}{l}n \\
\%\end{array}$ & 13 10,8 & ${ }^{20} 42,6$ & $\begin{array}{ll}2 & \\
& 3,3\end{array}$ & $\begin{array}{ll}1 & \\
& 6,7\end{array}$ & ${ }^{17} 34,7$ & 822,9 & $\begin{array}{l}77 \\
89,5\end{array}$ & $\begin{array}{l}138 \\
33,5\end{array}$ \\
\hline Outro local & $\begin{array}{r}n \\
\%\end{array}$ & $\begin{array}{ll}1 & \\
& 0,8\end{array}$ & $\begin{array}{ll}6 & \\
& \\
12,8\end{array}$ & $\begin{array}{ll}9 & \\
& 15,0\end{array}$ & ${ }^{3} 20,0$ & $\begin{array}{ll}0 & \\
& 0,0\end{array}$ & $\begin{array}{ll}3 & \\
& 8,6\end{array}$ & $\begin{array}{ll}0 & \\
& 0,0\end{array}$ & ${ }^{22} 5,3$ \\
\hline Total & $\begin{array}{l}\mathbf{n} \\
\%\end{array}$ & 120 & $\begin{array}{ll}47 & \\
& 100\end{array}$ & $\begin{array}{ll}60 & \\
& 100\end{array}$ & $\begin{array}{l}15 \\
100\end{array}$ & $\begin{array}{rr}49 \\
100\end{array}$ & $\begin{array}{l}35 \\
100\end{array}$ & $\begin{array}{l}86 \\
100\end{array}$ & $\begin{array}{l}412 \\
100\end{array}$ \\
\hline
\end{tabular}

Fonte dos dados: Inquérito Nacional Violência de Género, CIG, CesNova/FCSH-UNL.

O tipo de relação entre a vítima e o/a perpetrador/a condiciona os locais a que o/a perpetrador/a tem acesso. 0 mesmo perpetrador/a pode agir em locais com níveis diferenciados de privacidade. Para 389 casos de violência, obtiveram-se 412 respostas sobre o local onde a violência ocorreu (Quadro 1). A violência com caráter familiar ocorre em casa, um espaço tido como mais privado. É em casa que acontece parte considerável da violência cometida quer por maridos e companheiros das vítimas, atuais ou passados, quer por pais,mães, padrastos e madrastas da vítima, quer por outros familiares. A violência praticada por namorados e ex-namorados ocorre tanto em espaços públicos e na rua como em casa, o que mostra a conjugação entre locais com diferentes níveis de privacidade nas práticas de violência. Já a violência cometida por amigos/as e colegas da vítima dispersa-se por locais tendencialmente menos privados como os espaços públicos, a rua, a escola. É nolocal de trabalho que acontece parte considerável dos atos cometidos por outras pessoas (e.g., clientes, chefes). Indiscutivelmente, os atos cometidos por desconhecidos/as ocorrem na rua e em espaços públicos.

Relativamente aos motivos do ato e às reações que a violência suscita,não épossível apreender a sua variação no processo de vitimização. Porém, a pesquisa mostra que, consoante o/a perpetrador/a, a prática de violência suscita diferentes perceções sobre as causas e reações ao ato de violência (Quadro 2). Ao nível das causas da violência, o 
consumo de álcool é uma das principais justificações para os atos de violência praticados por maridos e companheiros da vítima, atuais ou passados. Paradoxalmente, o álcool não aparenta ser uma causa na violência no namoro. Aliás, os motores da violência no namorosãomais o ciúme e o sentimento de posse, motivos que também explicam a violência dos maridos/companheiros ou ex-maridos/ex-companheiros sobre as vítimas. Enquanto causas, ciúme e sentimento de posse sobre avítima distinguem-se. No período do namoro, a violência sofrida é percebidamais como uma consequência do ciúme do que do sentimento de posse, motivos que no contexto da conjugalidade parecem equiparar-se. O sentimento de posse sobre as vítimas é o principalmotivo da violência parental. Nos restantes contextos de perpetração, amá formação moral do/a perpetrador/a e a diferença de valores são apontadas como os motivos da violência contra as mulheres.

Quadro 2 睡 Motivo do ato e reação à violência por tipo de relação com o/a perpetrador/a

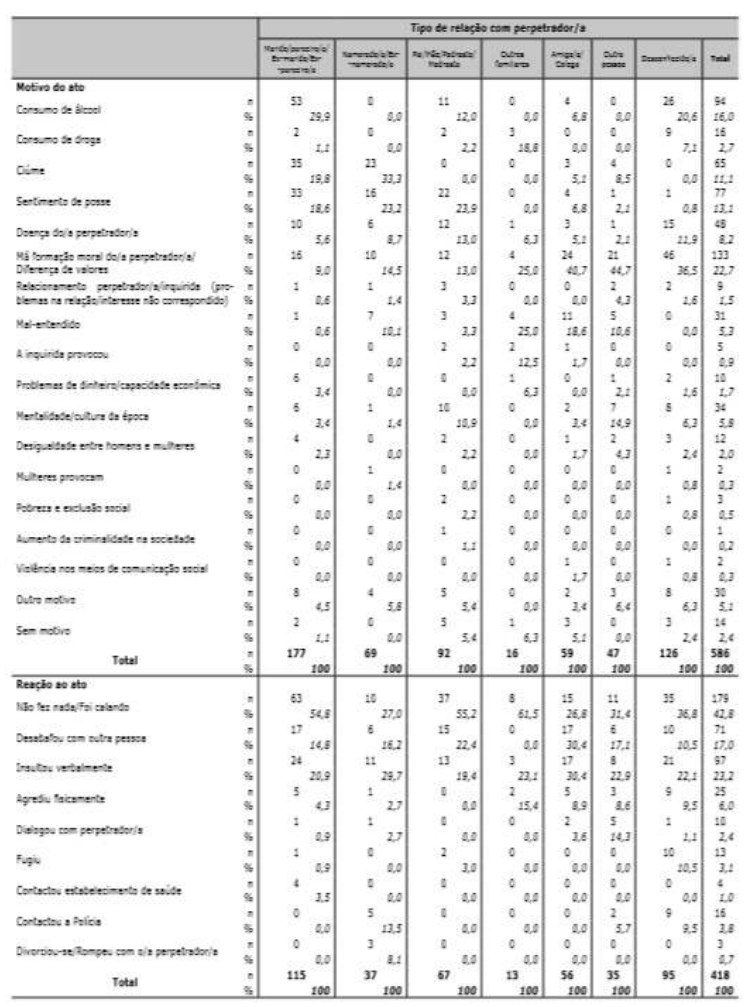

Fonte dos dados: Inquérito Nacional Violência de Género, CIG, CesNova/FCSH-UNL.

Se ao nível dos motivos da violência se constata uma diferenciação consoante o perpetrador/a do ato de violência, ao nível da reação à violência, predomina de forma muito clara a reaçãode não fazer nada e ir aguentando a situação, independentemente de quem perpetra a violência. Contudo, esta forma de reagir destaca-se nos casos de violência conjugal, de coabitação e no contexto familiar. Praticamente em todos os contextos de perpetração, o insulto verbal é a segunda reação mais referida. No namoro, a violência parece suscitar reações de menor aceitação da violência como o insulto verbal, contactar a polícia e o romper a relação. Apesar do reduzido número de casos registados, deve-se sublinhar que reações como o contacto com a polícia ou o romper a relação não surgem na violência no contexto da conjugalidade ou da coabitação. 


\section{Conclusão} vitimização, salientando-se a pesquisa da vitimização como um processo não circunscrito a determinado contexto social. No caso da violência sexual, sublinha-se a sua severidade, quer ao nível dos atos, quer ao nível das suas consequências para a vida das vítimas. Embora a vitimização seja em alguns casos uma condição de vida (e.g., Turner, Finkelhor et al., 2010), autores como Carbone-Lopez, Rennison et al. (2012) sublinham a agência do indivíduo e a possibilidade de este replicar ou interromper determinado padrão de vitimização.

31 A pesquisa exploratória aqui apresentada visou compreender o processo cumulativo da vitimização no curso de vida dasvítimas de violência sexual inquiridas no Inquérito Nacional Violência de Género. Estudos internacionais frisam a severidade da violência a que as vítimas de violência sexual estão expostas e respetivas consequências. Estes factos levam a pressupor que a investigação sobre vítimas sexuais evidenciaria casos severos de vitimização ao nível dos atos cometido e das implicações para o curso de vida da vítima. Por um lado, a informação analisada mostra a precocidade e a severidade da violência experienciada pelas vítimas sexuais, nomeadamente, as relações sexuais forçadas antes da maioridade da mulher e as situações que colocam a sua vida em risco. Por outro lado, as causas atribuídas e reações suscitadas pelo ato violento evidenciam a forma como os atos de violência são percecionados pelas mulheres. A isto acresce que a maior precocidade da vitimização, sobretudo de caráter sexual, pode condicionar quer a reação da vítima relativamente ao ato, quer a vitimização futura pelo mesmo ou por outro perpetrador.

32 A investigação permitiu identificar aspetos que devem ser objeto de uma análise mais pormenorizada. Primeiro, as mulheres vítimas de violência sexual são relativamente mais jovens do que as restantes vítimas. Segundo, a violência sexual declarada é maioritariamente composta por atos de assédio sexual; e as vítimas mais jovens declaram reações que indicam uma menor aceitação do ato de violência, incluindo o romperem a relação e o contatarem a polícia, o que, em parte, deve ser entendido como capacidade de agência por parte do indivíduo-vítima.

A vitimização declarada abarca práticas e contextos de violência distintos - e.g., violência do parceiro íntimo, violência parental, violência por pares, violência por desconhecidos/as. Embora todas as vítimas de violência sexual tenham sido vítimas de violência de género, pois a violência sexual assenta na discriminação do género feminino, a informação recolhida mostra que nem toda a violência declarada tem, necessariamente, um caráter de violência de género, de violência doméstica, ou de crime, já que coexistem casos de violência parental ou por pares com casos de violência nas relações de intimidade. Este facto fundamenta a realização de pesquisa sobre o processo de vitimização e a coexistência de conceitos de violência distintos.

O estudo da vitimização deve atender a aspetos sociais e históricos específicos do país que condicionam a experiência da violência pela vítima. A informação deve ser interpretada à luz da evolução recente da sociedade portuguesa (Patrício, 2010). Por um lado, a criminalização da violência doméstica e a crescente visibilidade da questão enquanto problema social potenciam uma maior consciência das mulheres sobre a sua vitimização. Por outro lado, a idade da vítima pode condicionar a declaração da

Forum Sociológico, 25 | 2014 
violência e a forma como esta reage à própria violência. É possível que, consoante a sua idade, as mulheres apresentem variações ao nível da aceitação e legitimação da violência (idem). Se a idade da vítima condiciona o início da vitimização, a idade atual pode determinar a perceção sobre o problema, refletindo-se quer na declaração da violência, quer nas reações e causas atribuídas ao ato. Paralelamente, as vítimas mais velhas podem não recordar factos ocorridos há mais tempo, situação que pode não verificar-se entre as informantes mais jovens. Aliás, em estudos aplicados a maiores de idade poderá dar-se uma valorização de situações ocorridas na idade adulta em detrimento das ocorridas na infância ou juventude.

A nível metodológico, na presente investigação não foi possível realizar análises de maior complexidade, pois a amostra de mulheres vítimas de violência sexual é relativamente pequena e o questionárionão está estruturado para aferir os objetivos propostos.

A pesquisa sobre vitimização deve considerar a especificidade do próprio fenómeno de vitimização, sobretudo no caso da violência sexual: a multiplicidade de atos, diferentes graus de severidade, a sua regularidade, os contextos de ocorrência, independentemente da idade da vítima; o não reconhecimento ou a não declaração propositada da violência. o predomínio de casos de assédio, por um lado, e o reduzido número de casos de relações sexuais forçadas, por outro, mostram a necessidade de realizar pesquisas sobre vitimização sexual, sobretudo as formas de caráter mais severo.

Como proposta de trabalho futuro, a pesquisa permite colocar várias questões. Por um lado, a necessidade de incrementar a investigação sobre violência sexual; por outro lado, a necessária complementaridade metodológica na pesquisa da vitimização enquanto processo cumulativo e paralelo à vida do indivíduo. A realização de pesquisa qualitativa permitirá compreender a dimensão do género nas práticas de violência e a sua influência no curso de vida da vítima, bem como as dinâmicas inerentes a um processo de vitimização.

\section{BIBLIOGRAFIA}

IV Plano Nacional Contra a Violência Doméstica. Resolução do Conselho de Ministros n. 100/2010, Diário da República, 1.ㄹ série, n.ํㅜ 243, 17 de dezembro de 2010, pp. 5763-5773.

ANDERSON, K. L. (2010), “Conflict, power, and violence in families”, Journal of Marriage and Family, 72, pp. 726-742.

BLACK, M. C.; K. C. Basile et al. (2011), The National Intimate Partner and Sexual Violence Survey (NISVS): 2010 Summary Report. Atlanta, National Center for Injury Prevention and Control, Centers for Disease Control and Prevention. 
CARBONE-LOPEZ, K.; C. M. Rennison et al. (2012), "The transcendence of violence across relationships: new methods for understanding men's and women's experiences of intimate partner violence across the life course", Journal of Quantitative Criminology, 28, pp. 319-346.

ELLONEN, N. e V. Salmi (2011), "Poly-victimization as a life condition: Correlates of polyvictimization among Finnish children", Journal of Scandinavian Studies in Criminology and Crime Prevention, 12, pp. 20-44.

FINKELHOR, D.; R. K. Ormrod et al. (2007a), "Poly-victimization: A neglected component in child victimization", Child Abuse \& Neglect, 31, pp. 7-26.

FINKELHOR, D.; R. K. Ormrod et al. (2007b), "Re-victimization patterns in a national longitudinal sample of children and youth", Child Abuse \& Neglect, 31, pp. 479-502.

KREBS, C.; M. J. Breiding et al. (2011), “The association between different types of intimate partner violence experienced by women", Journal of Family Violence, 26, pp. 487-500.

Lei n.ำ 7/2000, de 27 de maio. Quinta alteração ao Código Penal, Diário da República, 1. é série, n.. 123, 2000, pp. 2458.

Lei n.59/2007, de 4 de setembro. Vigésima terceira alteração ao Código Penal, Diário da República, 1. a série, n.o 170,2007 , pp. 6181-6258.

Lei n.ำ112/2009, de 16 de setembro. Estabelece o regime jurídico aplicável à prevenção da violência doméstica, à proteção e à assistência das suas vítimas, Diário da República, 1.․ série, n.․․ 180, 2009, pp. 6550-6561.

LISBOA, M. (coord.); Z. Barroso et al. (2009), Violência e Género. Inquérito Nacional sobre a Violência exercida contra Mulheres e Homens, Lisboa, Comissão para a Cidadania e Igualdade de Género.

MACHADO, C.; S. Caridade et al. (2010), "Violence in juvenile dating relationships self-reported prevalence and attitudes in a Portuguese sample", Journal of Family Violence, 25, pp. 43-52.

MACMILLAN, R. (2001), "Violence and the lifecourse: the consequences of victimization for personal and social development”, Annual Review of Sociology, 27, pp. 1-22.

PATRÍCIO, J. (2010), Violência Sexual no Feminino. Universos Temporais e Contextos Sociais, Lisboa, Faculdade de Ciências Sociais e Humanas, Universidade Nova de Lisboa. Dissertação de Mestrado em Estudos sobre as Mulheres.

TURNER, H. A.; D. Finkelhor et al. (2010), "Poly-victimization in a National Sample of Children and Youth", American Journal of Preventive Medicine, 38 (3), pp. 323-330.

WHITE, J. W. (2009), “A gendered approach to adolescent dating violence: conceptual and methodological issues", Psychology of Women Quarterly, 33, pp. 1-15.

WILLIAMS, L. M. (2003), “Understanding Child Abuse and Violence Against Women: a Life Course Perspective”, Journal of Interpersonal Violence, 18, pp. 441-450.

\section{NOTAS}

2. Estudo encomendado pela Comissão para a Cidadania e a Igualdade de Género e desenvolvido pela Faculdade de Ciências Sociais e Humanas da Universidade Nova de Lisboa, através do CesNova. Equipa de investigação: Manuel Lisboa (Coordenador), Zélia Barroso, Joana Patrício e Alexandra Leandro (Lisboa, Barroso et al., 2009). Inquérito realizado em 2007. Metodologia: aplicação de dois questionários a duas amostras independentes - 1000 homens e 1000 mulheres -, representativas da população de mulheres e homens com 18 ou mais anos, residentes em 
Portugal Continental. O questionário aplicado às mulheres recolheu informação sobre a vitimização por 62 atos de violência sexual, violência física, violência psicológica, discriminação sociocultural e ato experienciado pela mulher como violento.

3. Devido a diferenças metodológicas e ao nível da definição dos tipos de violência, a informação apresentada no artigo difere da publicada na sequência do Inquérito Nacional Violência de Género (Patrício, 2010).

4. Os atos de violência sexual considerados e a sua categorização em três géneros segue o Plano de Acção de Combate à Violência contra as Mulheres do Conselho da Europa (Patrício, 2010). Por outro lado, e dado o reduzido número, a agregação dos casos relacionados com pornografia, aborto ou gravidez forçados num único género permite integrá-los na análise proposta (Patrício, 2010).

5. Tipos de violência declarados: violência psicológica (39,3\%), violência sexual (36\%), violência física (12,1\%), discriminação sociocultural (12,1\%), atos considerados violentos (0,4 \%) (Patrício, 2010).

1. Artigo baseado em duas comunicações apresentadas em congresso: "Sexual violence against women: a Portuguese study", comunicação apresentada na 10th Conference of the European Sociological Association, Universidade de Genebra, Suíça, 08/09/2011; e "Violência contra as mulheres: contextos e processos de violência", comunicação apresentada no Colóquio Violência doméstica sobre mulheres: respostas, dilemas e desafios, organizado pelo Centro de Estudos Sociais da Universidade de Coimbra na Faculdade de Economia da Universidade de Coimbra, Portugal, 28/10/2011.

\section{RESUMOS}

Nas últimas décadas, a violência contra mulheres foi constituída em problema social. Atualmente é objeto de políticas internacionais e nacionais no âmbito da violência doméstica. $\mathrm{O}$ artigo tem dois objetivos. Primeiro, a discussão sobre a vitimização enquanto processo cumulativo, desenvolvido ao longo da vida da vítima. Segundo, e de modo a perceber contextos e processos de vitimização distintos, comparam-se os casos de violência física, sexual e psicológica, declarados por mulheres vítimas de violência sexual no Inquérito Nacional Violência de Género, pesquisa realizada em 2007 (CesNova, FCSH-UNL/CIG). A análise permite concluir que as vítimas sexuais são mais jovens do que as outras vítimas e expõe a precocidade e severidade na sua vitimização.

In the last decades, violence against women has become recognized as a social problem, target of international and national policies concerning domestic violence. The paper has two goals. First, to discuss victimization as a cumulative process developed across victim's life span. Second and in order to distinguish victimization contexts and processes, it is established a comparison among situations of physical, sexual and psychological violence. The analysis focuses situations of violence declared by sexual violence victims in the National Survey on Gender Violence, research carried out in 2007 (CesNova, FCSH-UNL/CIG). This research has led to the conclusion that sexual violence victims are younger than other victims, highlighting a premature and severe victimization. 
ÍNDICE

Keywords: violence against women, sexual violence, national survey, Portugal

Palavras-chave: violência contra as mulheres, violência sexual, inquérito nacional, Portugal

\section{AUTOR}

\section{JOANA AGUIAR PATRÍCIO}

Instituto Universitário de Lisboa (IUL-ISCTE), Centro de Investigação e Estudos de Sociologia (CIES-IUL), Lisboa, Portugal(joana.a.patricio@gmail.com) 